\title{
The Feasibility of Irradiated Bioplastics As Future Packaging Material
}

\author{
Nur Ain Hamiruddin, Siti Amira Othman
}

\begin{abstract}
For bioplastic materials, the role of radiation in shaping their performance has received growing scholarly interest. Notably, bioplastic materials refer to substances manufactured using organic biomass components. To prepare these substances, different processes are implemented. For hightechnology firms, specialty plastics are required, especially those with specific responses upon being exposed to radiation. In the recent years, the majority of food packaging materials have received approval relative to the aspect of irradiation. However, the extent to which these substances could be safe has proved challenging to unearth; with the industry charged with food and regulation guidelines on focus. of importance to note is that the bioplastic materials come with several benefits. Some of these merits include the affirmation that they do not generate toxic fumes and that they also reduce the emission of carbon dioxide, which would be the case if other unrelated materials were used. The central aim of this review paper is to examine the degree to which irradiated bioplastic materials could prove feasible relative to their use as packaging materials in the future.
\end{abstract}

Index Terms: Irradiated, Bioplastics, Packaging, Food.

\section{INTRODUCTION}

In the packaging of products and other fields (such as the pharmaceutical, medical, and food sectors), ionizing radiation has been employed but product exposure is restricted to certain durations (Murano, 1995). Imperatively, radiation is a food treatment procedure due to its penetrative capacity. However, not all forms of radiation could prove applicable to food situations [1]. The U.S. Food and Drug Administration (FDA) permits three sources of ionizing radiation; especially for food sterilization and pasteurization. These include the use of the electronic beam (e-beam), $\mathrm{X}$ rays, and gamma rays $(\gamma)$ [2]. Imperatively, most of the radioactive materials produce gamma rays due to their highenergy nature. Some of these materials include $137 \mathrm{Cs}$ (0.662 MeV), Cesium-137, 60Co sources, (1.17 and 1.33 $\mathrm{MeV}$, and Cobalt-60. The penetration capacity of these rays, upon exposure to food, could extend to some feet. Regarding the case of the X-rays, they are emitted by electrons and can penetrate thick food materials. However, the energies at which they (the X-rays) are generated do not exceed $5 \mathrm{MeV}$. Relative to the use of the e-beam, it arises from electrical conversion and acceleration and operates within the limit of $10 \mathrm{MeV}$ [3]. In some of the previous scholar studies (such as Raghu et al., (2016)), most of the findings demonstrate that the electronic beam exhibits a more pronounced impact because the irradiation beam loses

Revised Manuscript Received on July 22, 2019

Nur Ain Hamiruddin, Universiti Malaysia Perlis, Kampus Uniciti Alam, Sungai Chuchuh, 02100, Padang Besar, Perlis.

Siti Amira Othman, Faculty of Applied Sciences and Technology, Department of Physics and Chemistry, Universiti Tun Hussein Onn Malaysia, Pagoh Educational Hub, Panchor, 84000 Pagoh, Muar Johor a lot of electronic energy, exceeding the impact posed by irradiation from the gamma rays.

\section{TYPE OF BIOPLASTICS}

Potatoes and nuts form some of the notable sources of bioplastic. These materials contain renewable starch [5]. Hence, they form effective materials for packaging, having undergone modification to develop films that offer adequate mechanical properties associated with high-percentage flexture and strength. To process starch, some of the materials that are added include plasticizers and flexibilizers; including glycerin and sorbitol. The addition leads to the formation of the Thermoplastic kanji (TPS), which could be applied in the place of polystyrene (PS). In industrial applications, some of the materials that have been sued widely include polyvinyl alcohol or polyethylene-vinyl alcohol, which are starch-based materials. Specific examples of the industrial applications where they have been used include foaming and blowing films, blow molding, injection molding, and extrusion applications [6].

Through bio-polyesters, there results a chemical process of bioplastic synthesis. The majority of the resultant biopolyester becomes polyylactic acid (PLA), which is used to produce renewable packaging materials [7]. For the case of classical materials for packaging, their origin entails mineral oils, which could be produced from monomer- or fermentation-related renewable sources. Despite its promising nature, the process proves les economical because monomer production attracts high costs.

To produce PLA plastics, agricultural products are harvested. Some of these materials include corn and wheat, which are rich in starch. The process of producing the plastic entails corn or related material conversion to form dextrose, a step that precedes the fermentation process responsible for lactic acid formation. The resultant PLA constitutes biodegradable and thermoplastic aliphatic polyester, which gains application in packaging [8]. It is also notable that the lactic acid monomer could undergo the process of ring opening lactide polymerization or be polycondensed directly to yield the PLA pellets [9]. Indeed, PLA forms one of the renowned and first commercial bio-based polymers that have gained massive application and commercialization, lending its usage to the coating, film, and injectable objects. Due to its growing use, it has ended up being used mostly as a wrapping material and replaced polyethylene terephthalate or high-density polyethylene.

\section{EFFECT OF RADIATION ON POLYMERS}

Should irritation be experienced, most of the packaging materials are likely to be affected; especially regarding their

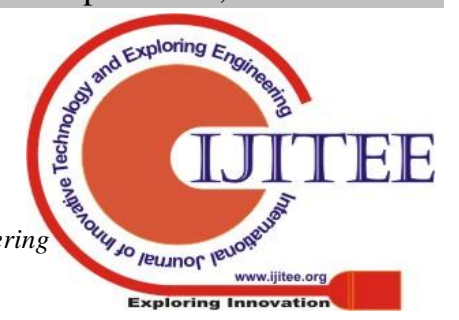


functionality and integrity towards preventing microbial or chemical pollution. However, not all polymer properties might be affected by the radiation. Instead, it (the radiation) could prove beneficial. Of importance is that polymers form the majority of food packaging materials. Some of the chemical changes to which such materials tend to be exposed include those that arise from ionizing radiation, a product of two reactions: swelling (degeneration) and cross (polymerization) reactions. In the inert or vacuum scenarios, the radiation-led polymer spread tends to dominate. In the presence of air, the separation of chain tends to dominate. Imperatively, the two reactions occur randomly and factors that determine their success include the level of atmospheric oxygen and the dose rate. In an inactive or vacuum setting, dominant cross-polling ideas aid in the issuance of the recent exemption request relative to the specifications in 21 CFR 170.39, which governs the packaging of food contact materials in both frozen conditions and under environments free of oxygen, as well as vacuums.

When atmospheric oxygen is present, the polymerled deterioration leads to radiolytic product formation. Indeed, these products result from irradiation processes at crucial stages, ensuring that they migrate into the target food. Parameters that are affected include the safety, taste, and smell of the illuminated food. As irradiation occurs, the polymer is expected to be lowered optimally to yield radiolytic products. As such, the migration of the radiological products and the polymer is worth evaluating in the form of a pre-market safety assessment before being used; especially in environments involving oxygen presence and high doses.

In the recent past, there has been a rapid growth in the scholarly investigations targeting the effects of radiation on polymer materials. Notably, the impact that radiation poses on polymers exists in the form of the physics of chemical radiation, as well as the field of radiation. Physics radiation seeks to understand both lower energy ultraviolet radiation and high energy ionization radiation. In relation to the case of ionization radiation, it becomes important to acknowledge that the ionic or radical events of material formation are worth considering, as well as reactions that follow, as they inform how radiation chemistry's parts could be restructured in their entirety. For the case of ultraviolet radiation, there is a significant difference in the outcomes compared to situations involving photocomics and photophysics. Some of the notable and affected container areas include the energy transfer phenomena, the radiation deactivation process, and the excited state formation [10].

\section{PACKAGING MATERIALS}

In the food packaging process, the main objective lies in the maintenance of food quality and safety. Hence, packaging reflects a technology, art, and science for protecting products relative to their distribution, use, sale, and storage. From a business perspective, the packaging process plays a crucial role because it provides room for the transfer of the goods from the plant to the end-users [11]. Hence, maintaining the food quality, diversity, and safety forms a central objective of the packaging process. The latter objective accounts for recent trends in which the packaging process has gained application relative to the need to ensure that the nutritional information and parts of the product are delivered to the customers. Currently, a traditional packaging value chain is characterized by little interaction among functions such as sales and marketing product development, logistics, operations, and purchases Regarding packaging, the step exhibits a close relationship with brand equity organizations and seeks to add value, rather than introduce costs. Hence, the current state of product packaging emphasizes flexibility via the use of materials such as glass bottles, wraps, labels, and corrugated boxes.

Of importance o note is that glass forms one of the most common packaging materials. At very high temperatures, materials such as alumina, calcium carbonate, sodium carbonate, and silica are heated to ensure that the mixture melts and forms a thick liquid, which is transferred into the mold. Similarly, glass slabs are recycled for use as raw materials for manufacturing new glass. In food packaging, the glass materials that are used are coated and abrasion surfaces removed. The role of the coating process lies in the need to strengthen the glass containers; hence reduced damage. On the other hand, enhanced burst resistance aids in achieving thinner glass material, making it easy to transport and also dispose [12]. However, the emergence of rigid plastic has seen the use of glass a major packaging material diminish; with the material (glass) mostly used by alcoholic beverage manufacturers.

To prepare the plastic materials, additional polymerization or reinforcing polymerization is employed; having targeted monomer units. During the reinforcing polymerization procedure, condensing reactions lead to the growth of polymer chains; occurring between molecules. In turn, low-molecular weight byproducts form and include methanol and water. Indeed, the process involves monomers and they are expected to have at least two functional groups. Examples of such groups include carboxylic groups, amines, or alcohol.

In food packaging, various types of plastics are employed. Examples include ethylene vinyl alcohol, polyamide, polystyrene, polyvinylidene, polyvinyl chloride polyester, and polyolefins. Whereas over 30 plastic types have gained application as wrapping materials, the most commonly used types include polyesters and polyolefins. For the packaging of mineral water and drinks, the most commonly used polyesters are PET. For carbonated beverages and plastic bottles, PETE is the most common type of polyesters that has been used [13].

For decades, biodegradable polyesters have also been used; especially those manufactured from starch and cellulose. Upon exposure to moisture, the rice-based polymer tends to swell and change. Examples of such polymers include dextrin, hydroxylpropylene starch, and amylase. Apart from renewable raw materials, biodegradable products are broken down to yield environmentally friendly materials. Some of these materials include high-quality compost and water [14]. Starch-based polymers also include valvic acid (PHB / V), PHB copolymers, polyhydroxyalcano (PHA), polyhydroxibacterial (PHB) and polylactide. Upon fermenting lactic acid, the result polyuria is stable and unlikely to be damaged by moisture. An example of the lactic acid bacteria that is fermented is the case of starch bacteria (Auras et al., 2004). In relation to PHB / V, PHB and PHA, they can be produced through starch fermentation. For the case 
of biodegradable films, their production also involves the use of chitosan, a biopolymer that has continually gained application in pharmaceutical organizations [15]. It is also notable that chitosan aids in establishing composite materials. Some of these materials include alloys. A biodegradable polymer that is also used entails a thin material layer that is placed between or inside food components. The thin layer constitutes edible material and bars against humidity, as well as other food solvents and oxygen. The eventuality is that the materials, upon use, become food coatings. However, they can also be disposed off when placed as continuous layers between selected food components [16]. Hence, the food layers exist in the form of edible films and can be used as gas aroma barriers too [17]. Indeed, animals and plants from which the edible films are developed include collagen and gelatin (connective tissue, tendons, and skin substitutes), zein (corn protein), and whey (milk protein) [18].

To develop synthetic polymers, bio-polymers are incorporated. Also, materials such as cellulose and starch, which are biodegradable, are incorporated. Imperative to highlight is that bioactive compounds have gained several applications. In situations where they are mixed with swollen compounds, they aid in enhancing plastic molecules. Upon encountering humidity, the bioactive compounds end up breaking down the target plastics [19]. The factor or motivation behind the use of biodegradable polymers is that there is a need to curb residual and soluble wastes by resorting to the use of renewable materials in the place of non-renewable raw materials that include coal, oil, and natural gas. Currently, most of the bioplastics have proved expensive compared to petroleum-based polymers. As such, the cost of packaging tends to be here when these materials require replacement. Hence, biodegradable packaging seems impractical but it comes with beneficial outcomes, pointing to the criticality of embracing this trend in industrial situations.

\section{REGULATIONS FOR PACKAGING MATERIAL IRRADIATION}

U.S. Food and Drug Administration (FDA) [20] permits the use of irradiation as a means of improving food security and expanding the lifespan of certain foods. In addition, the irradiation of certain fruits and vegetables can prevent growth and maturation of maturity.

Safety of food packaging materials exposed to irradiation is found in several parts of the Federal, Food, Drug and Cosmetic Act (Act). Section 201 (a) of the Act defines "food additives" as "any use of the substance in question which results or is expected to produce, directly or indirectly, into components or otherwise affect any food features including intended sources of radiation for such use ". Under Section 409 (a) of the Act, food is deemed to be merged, and therefore prohibited from interstate commerce if it has been intentionally illuminated, unless the irradiation is performed in compliance with the applicable food additive regulations under the terms of use set out in the regulation. The main regulation which includes the use of irradiation in the production, processing and handling of food is the Federal Legislative Behavior (CFR) 179. This rule outlines the general provisions for food irradiation, the FDA list approval has provided additional additives for irradiation, and illustrates radiation and radiation sources, including ionization, radiofrequency, ultraviolet and pulsed light radiation.

In particular, 21 CFR 179 states that the irradiation of both feedstuff and packing in contact with food is subject to premarket approval prior to introduction of food into intermediate trading. It also states that the current good manufacturing practices for irradiating food include three things. First, the manufacturer must comply with the general requirements of well-manufactured manufacturing practices for manufacturing, packaging or human food, found in 21 CFR 110. Secondly, the manufacturer must ensure that the radiation dose used is the minimum required dosage to achieve the impact technique recommendations and not above the level stated in the rule. Third, packaging materials used during radiation treatment must comply with the requirements contained in $21 \mathrm{CFR} 179.45$, specifications for effective food contact notification, or regulatory exclusion (TOR) limits.

\section{CONCLUSION}

Better food safety microbiology can be achieved by using irradiation in the production of several types of raw processed foods such as chicken, meat and meat products, fish, seafood, fruits, and vegetables. In fact, due to newly borne pathogens in fresh results, there is increased interest in using irradiation to improve the safety of fresh products [21]. However, food manufacturers must ensure that irradiated foodstuffs and packaging materials used during the irradiation process are permitted for use.

\section{ACKNOWLEDGMENT}

The authors would like to thank the Universiti Malaysia Perlis and Universiti Tun Hussein Onn Malaysia for facilities provided and gratefully acknowledged the financial support a research grant (H074) that make the research possible.

\section{REFERENCES}

1. Urbain, W.M. 1986. Food irradiation. Orlando, FL., Academic Press, Inc

2. Komolprasert, V. 2007. Packaging for food treated with ionizing radiation. In: Packaging for non-thermal processing of food, (Ed.) J.H Han, Blackwell Publishing. Ames, IA, pp. 1-16.

3. O'Donnell, American Chemical Society. Washington, D.C., pp. 1-13 O'Donnell, J.H., Sangster, D.F. 1970. Principles of radiation chemistry, Edward Arnold, London.

4. Raghu, R, Archana, K., Sharanappa,C., Ganesh., S, Devendrappa., H (2016). Electron beam and gamma ray irradiated polymer electrolyte films: Dielectric properties. Journal of Radiation Research and Applied Sciences. Volume 9, Issue 2, April 2016, Pages 117-12

5. Park, H., Li, X., Jin, C., Park, C.-Y., \& Cho, W.-J. (2002). Preparation and properties of biodegradable thermoplastic starch/clay hybrids. Macromolecular Materials and Engineering, 287, 553-558. http://dx.doi.org/10.1002/1439- 2054(20020801)287:83.0.CO;2-3

6. Mensitieri, G., Di Maio, E., Buonocore, G. G., Nedi, I., Oliviero, M., Sansone, L., \& Iannace, S. (2011). Processing and shelf life issues of selected food packaging materials and structures from renewable resources. Trends in Food Science \& Technology, 22, 72-80.

7. Jamshidian, M., Tehrany, E. A., Imran, M., Jacquot, M., \& Desobry, S. (2010). Poly-lactic acid: Production, applications, nanocomposites, and release studies. 
8. Rhim, J. W., Hong, S. I., \& Ha, C. S. (2009). Tensile, water vapour barrier and antimicrobial properties of PLA/nanoclay composite films. Food Science and Technology, 42, 612-617.

9. Rasal, R. M., Janorkar, A. V., \& Hirt, D. E. (2010). Poly(lactic acid) modifications. Progress in Polymer Science, 35, 338-356. http://dx.doi.org/10.1016/j.progpolymsci.2009.12.003.

10.Clough, R., Shalaby, S. W., eds., (1990) "Radiation Effects on Polymers, (1991) " ACS Symposium Series 475, ACS Washington, D.C.,

11.Potter, N. N., \& Hotchkiss, J. H. (1995). Food science. New York: Chapman \& Hall.

12. McKown K.M. Laura D. Carbone, Juan Bustillo, Jerome M. Seyer, Andrew H. Kang, Arnold E. Postlethwaite (2001). Induction of immune tolerance to human type I collagen in patients with systemic sclerosis by oral administration of bovine type I collagen.

13. Van- willige R. W. G., Linssen J. P. H., Meinders M. B .J., Vander S. H. J., and Voragen A. G. J. (2002). Influence of flavor absorption on oxygen permeation through LDPE, PP, PC and PET plastics food packaging. Food Additives and Contaminants. 19:303-13.

14. Tharanathan, R. N. (2003). Review e biodegradable films and composite coatings: Past, present and future. Trends in Food Science \& Technology, 14, 71-78.

15.Patel, V.R. and Amiji, M.M. (1996). Preparation and characterization of freeze dried chitosan poly(ethylene oxide) hydrogels for site-specific antibiotic delivery in the stomach. Pharmaceut. Res. 13: 588-593.

16.Potter, N.N. and Hotchkiss, J.H. (1995). Food Science, Fifth Edition. Chapman \& Hall, New.

17. Guilbert, S. (1986). Technology and application of edible protective films. In Mathlouthi, M. (Ed.), Food Packaging and Preservation, London, UK: Elsevier Applied Science.371-394.

18. Kester, J. J. and Fennema, O. R. (1986). Edible films and coatings: A review. Food Technology 40(12): 47-59.

19.Bourtoom, T. (2008). Edible film and coatings: Characterstics and properties. Int. Food Res. J. 15(3). 1-12.

20. Food and Drug Administration (FDA). (2002) Guidance for industry: Preparation of premarket submission for food contact substances: Chemistry recommendations, Center for food safety and applied nutrition, Office of food additive safety: College Park, MD. U.S. Food and Drug Administration..

21.Bailey, Allan B., Chanderbhan, Ronald, Collazo-Braier, Nancy, Cheeseman, Mitchell A., Twaroski, Michelle L. 2005. The use of structure-activity relationship analysis in the food contact notification program. Regulatory Toxicology and Pharmacology 42(2):225-235.

\section{AUTHORS PROFILE}

First Author Currently pursue master study at University Malaysia Perlis. Actively published paper at well-known scopus journal.

Second Author Currently working as a lecturer in Universiti Tun Hussein Onn Malaysia. Also as a Head of research focus group for Radiation Monitoring and Protection (RMP). 